\title{
Design of School Information System Using Waterfall Method (Case study: MTsN 8 Bantul)
}

\section{Rancang Bangun Sistem Inormasi Sekolah Menggunakan Metode Waterfall (Studi kasus : MTsN 8 Bantul)}

\author{
Rovalia Adhella Attya Amanda', Arizona Firdonsyah² \\ [arovalia@gmail.com ${ }^{1}$, arizona@unisayogya.ac.id ${ }^{2}$ ] \\ Program Studi Teknologi Informasi, Fakultas Sains dan Teknologi, Universitas 'Aisyiyah, Yogyakarta, Jl. Siliwangi (Ring \\ Road Barat) No. 63, Yogyakarta, Indonesia
}

\begin{abstract}
The development of technology is now getting wider and starting to spread in various fields, one of the areas affected by the development of technology is education. This development has the intention of streamlining existing activities. The design of the school information system at MTsN 8 Bantul is to facilitate activities in data processing at the school. Using the waterfall method is expected to make it easier in this research, as well as telling, analyzing, and classifying problems as a supporting method. The result of this research is a school information system design.
\end{abstract}

Keywords - Industry 4.0; School Information System; Wterfall

\begin{abstract}
Abstrak. Perkembangan tenologi kini semakin luas dan mulai merambah diberbagai bidang, salah satu bidang yang terkena dampak dari perkembangan teknologi adalah pendidikan. Perkembangan ini memiliki maksud untuk mengefisienkan kegiatan yang ada. Pembuatan rancang bangun sistem informasi sekolah di MTsN 8 Bantul ini untuk memudahkan kegiatan dalam pengolahan data di Sekolah tersebut. Menggunakan metode waterfall diharap dapat mempermudah dalam penelitian ini, serta menuturkan, menganalisa, dan mengklasifikasi masalah sebagai metode pendukung. Hasil dari penelitian ini adalah sebuah rancang bangun sistem informasi sekolah.
\end{abstract}

Kata Kunci - Industri 4.0; Sistem Informasi Sekolah; waterfall

\section{PENDAHULUAN}

Masyarakat kini sudah mulai mengikuti perkembangan jaman terutama di era serba digital pada saat ini, perkembangan digital di industri 4.0 ini menuntut masyarakat untuk berani bersaing didunia glogal. Aspek yang sangat berpengaruh dalam persaingan global terutama di era industri 4.0 ini adalah kemampuan berkomunikasi, berkolaborasi, berpikir kritis dan menyelesaikan masalah, serta memiliki kreativitas dan berinovasi. Kemudahan dalam melakukan sesuatu yang diberikan hampir semua menggunakan IoT atau Internet of Thing [1]. Seluruh aspek mulai terpengaruh dengan adanya digitalisasi, seperti sekolah yang kini mulai menggunakan sistem informasi digital.

Sistem adalah media yang dapat berpengaruh dalam suatu perkembangan teknologi. Sistem memiliki arti bahasa yakni (systēma) yang berasal dari bahasa Latin serta (sustēma) yang berasal dari bahasa Yunani. Sistem sendiri merupakan kesatuan yang terdiri komponen atau elemen yang dihubungkan bersama untuk memudahkan aliran informasi, materi atau energi untuk mencapai suatu sedangkan informasi merupakan data yang telah diolah menjadi suatu bentuk yang penting bagi pengguna dan mempunyai nilai yang nyata atau dapat dirasakan manfaatnya dalam keputusan-keputusan yang akan datang[2]. sistem sendiri menyediakan informasi yang dapat digunakan untuk memanajemen dalam mengambil suatu keputusan selain itu juga untuk menjalankan operasional pada perusahaan, di mana banyak orang yang kombinasikan sistem tersebut, selain orang ada juga teknologi informasi, dan prosesur yang saling terorganisasi. Sistem informasi juga terdapat data yang telah dikumpulkan agar dapat saling terkait dan menghasilkan informasi yang dapat dimanfaatkan [3].

Digitalisasi data adalah mengubah cara seseorang dalam mengolah data dari konvensional atau kertas ke modern atau menggunakan perangkat digital dimana cara pemerintah untuk menggiring dunia pendidikan agar mengikuti era industri 4.0 ini [4]. Digitalisasi ini bertujuan juga untuk memudahkan para pengajar untuk mengolah data terutama dimasa pandemi, selain itu dengan adanya digitalisasi data dapat dengan mudah mengirimkan perkembangan sekolah pada pusat atau kemendikbud. Digitalisasi yang diadakan di Indonesi ini diharapkan dapat meningkatkan kualitas pendidikan di Indonesia [5].

Digitalisasi tidak hanya berlaku untuk guru, kini siswa pun juga sudah terkena pengaruhnya, contoh sederhananya adalah adanya tugas menggunakan media google form atau juga pengumpulan tugas menggunakan format word. Hal ini dilakukan agar generasi muda tidak gagap teknologi dan tidak ketinggalan jaman dalam menggunakan media digital. 


\section{METODE}

Penelitian ini menggunakan beberapa metodologi. Metodologi sendiri adalah ilmu yang digunakan untuk memproleh kebenaran dan memecahkan masalah dengan tata cara tertentu[6]. Pembuatan rancang bangun ini hanya menggunakan 2 metodologi yakni Metode Deskriptif untuk pembuatan laporan dan Metode Waterfall untuk pembuatan rancang bangunnya.

Metode Deskriptif ialah membuat deskripsi, gambaran atau lukisan secara sistematis, faktual dan akurat mengenai fakta-fakta, sifat-sifat, observasi, interview, angket, dan lainnya serta hubungan antar fenomena yang diselidiki [7].

Metode Waterfall adalah sebuah metode yang pengembangan perangkat lunaknya berurutan melewati fase perencanaan, pemodelan, implementasi dan pengujian. Sedangkan menurut Pressman, Roger S Metode Waterfall adalah perangkat lunak yang dikembangkan secara berurutan, dengan melihat dari adanya fenomena air dimana kemajuan akan terus mengalir seperti air kebawah layaknya air terjun, hal ini tentunya harus melewati fase perencanaan, pemodelan, implementasi, dan pengujian [8] [9]. Metode Waterfall beberapa, tahapan dari metode Waterfall sendiri dari 5 tahap seperti Gambar 1. [10]

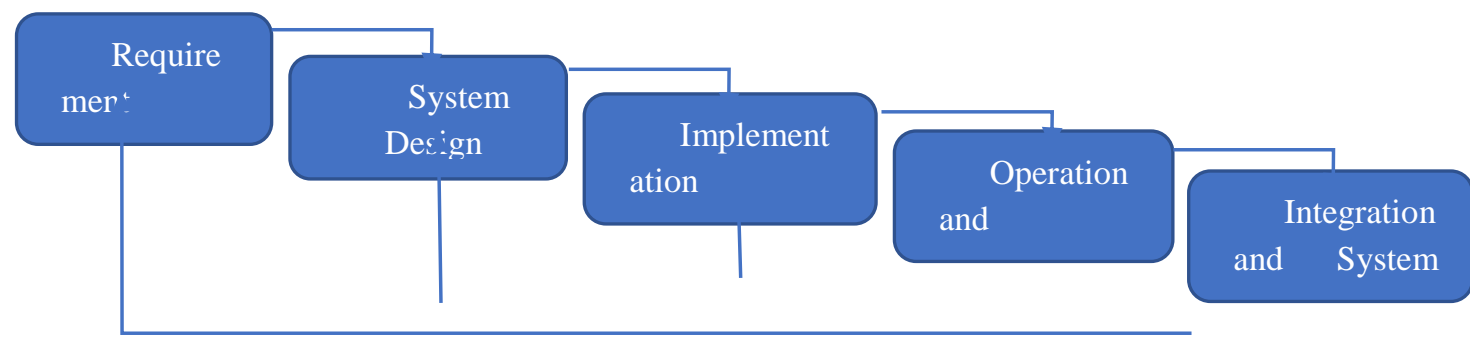

Gambar 1. Diagram tahapan dari metode Waterfall

\section{A. Requirement Analysis}

Analisis kebutuhan ini diperlukan dalam pembuatan software agar dapat diketahui apafungsi dan batasan pada sebuah software, selain itu tujuan lain adalah mengetahui apa saja yang dibutuhkan oleh pengguna. Dalam Analisis kebutuhan biasanya informasi didapatkan dengan cara survei, diskusi, hingga wawancara.

\section{B. System Design}

Desain sistem adalah tahap lanjutan dari analisis kebutuhan. Tahap ini bertujuan untuk menentukan Hardware yang tepat bagi sistem, selai itu tahap ini membantu untuk menentukan persyaratan pada sistem dan membuat definisi arsitektur pada sistem secara keseluruhan.

\section{Implementation}

Implementasi adalah tahap ketiga. Tahap ini bertujuan untuk membuat unit dimana unit adalah program kecil. Unit nantinya akan terintegrasi ketahap berikutnya selain itu unit akan dikembangkan dan di ujicoba fungsionalitasnya hal ini disebut unit testing

\section{Integration and System Testing}

Integrasi dan pengujian sistem adalah tahap dimana unit yag sudah dites langsung di kembangkan yang diintegrasikan ke suatu sistem. Setelah pengintegrasian unit yang akan melakukan pengecekan setiap kegagalan yang terjadi.

\section{E. Operation dan Maintenance}

Oprasi dan pemeliharaan adalah tahap terakhir dari tahapan metode waterfall ini. Software yang sudah lulus dalam pengcekan akan langsung dijalankan dan dilakukan pemeliharaan. Hal ini dibutuhkan termasuk dalam pembenahan sistem yang gagal dimana kegagalan tersebut tidak ditemukan pada tahap sebelumnya. 


\section{HASIL DAN PEMBAHASAN}

Kegiatan atau proses bisnis yang berlangsung dimulai dari awal yakni penginputan data siswa hingga penerima laporan oleh orang tua/wali siswa. Bidang yang memiliki ketekaitan antara satu dengan yang lainnya seingga sistem ini juga bertujuan untuk menyimpan data. Alur kegiatan sistem dapat digambarkan dan dijelaskan melalui Gambar 2 .

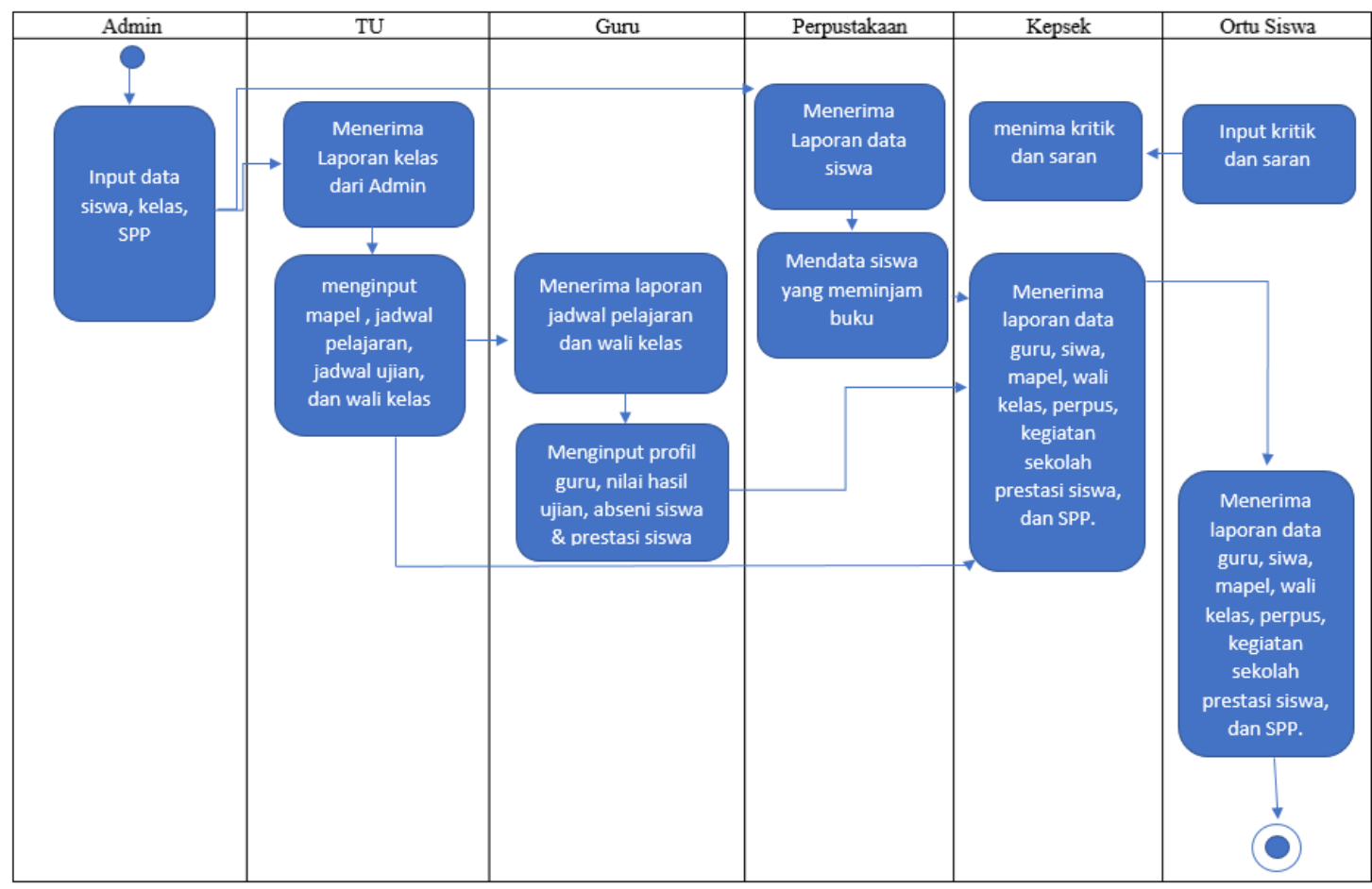

Gambar 2. diagram proses bisnis

Gambar 2. menjelaskan mengenai diagram proses bisnis sistem informasi yang akan dibuat. Diagram proses bisnis sistem informasi sekolah ini memiliki beberapa aktor. Aktor tersebut terdiri dari administrasi, tata usaha, guru, perpustakaan, kepala sekolah, orangtua atau wali siswa. Aktor memiliki perannya masing-masing.

1. Administrasi

bertugas menginput data siswa, kelas, SPP.

2. Tata Usaha

bertugas menginput mata pelajaran siswa dan guru, jadwal pelajaran, jadwal ujian, dan wali kelas. Selain menginput tata usaha juga dapat menerima laporan data kelas dari administrasi.

3. Guru

memiliki tugas menginput profil guru, menginput hasil nilai ujian, menginput absen siswa dan prestasi siswa. Selain menginput guru juga bisa menerima laporan jadwal pelajaran untuk guru dan data wali kelas.

4. Perpustakaan

perpustakaan hanya memiliki satu tugas yakni mendata siswa yang meminjam dan mengembalikan buku serta mendata denda yang harus dibayar oleh siswa. Tak hanya menginput dan melaporkan data perpustakaan juga dapat menerima laporan data siswa dari administrasi untuk pendataan peminjaman buku di perpustakaan.

5. Kepala Sekolah

Kepala Sekolah sendiri hanya dapat menerima laporan data dari seluruh bagian staff di sistem informasi sekolah baik dari laporan bidang administrasi, tata usaha, guru, perpustakaan. Kepala sekolah juga dapat menerima kritik dan saran yang diberikan oleh orang tua siswa.

6. Orang tua atu wali siswa

Peran dari Orang tua atu wali siswa yang hampir sama dengan kepala sekolah yakni menerima laporan dari berbagai bidang yang ada di MTsN 8 Bantul, namun pada orang tua dapat memberikan kritik dan saran yang ditujukan oleh sekolahan. 
Procedia of Engineering and Life Science Vol. 1. No. 2 Juni 2021

Seminar Nasional \& Call Paper Fakultas Sains dan Teknologi (SENASAINS 2nd)

Universitas Muhammadiyah Sidoarjo

Pembuatan Use Case pada rancang bangun Sistem Informasi Sekolahan. Use Case adalah sebuah teknik pemodelan yang digunakan untuk menjelaskan apa yang harus dilakukan sebuah sistem baru. Model use case dibangun melalui sebuah proses iterasi selama diskusi antara pengembang sistem dan customer ( dan / atau end user) berdasarkan sebuah kebutuhan khusus yang disetujui semuanya. Berikut adalah Use Case pada diagram 1.

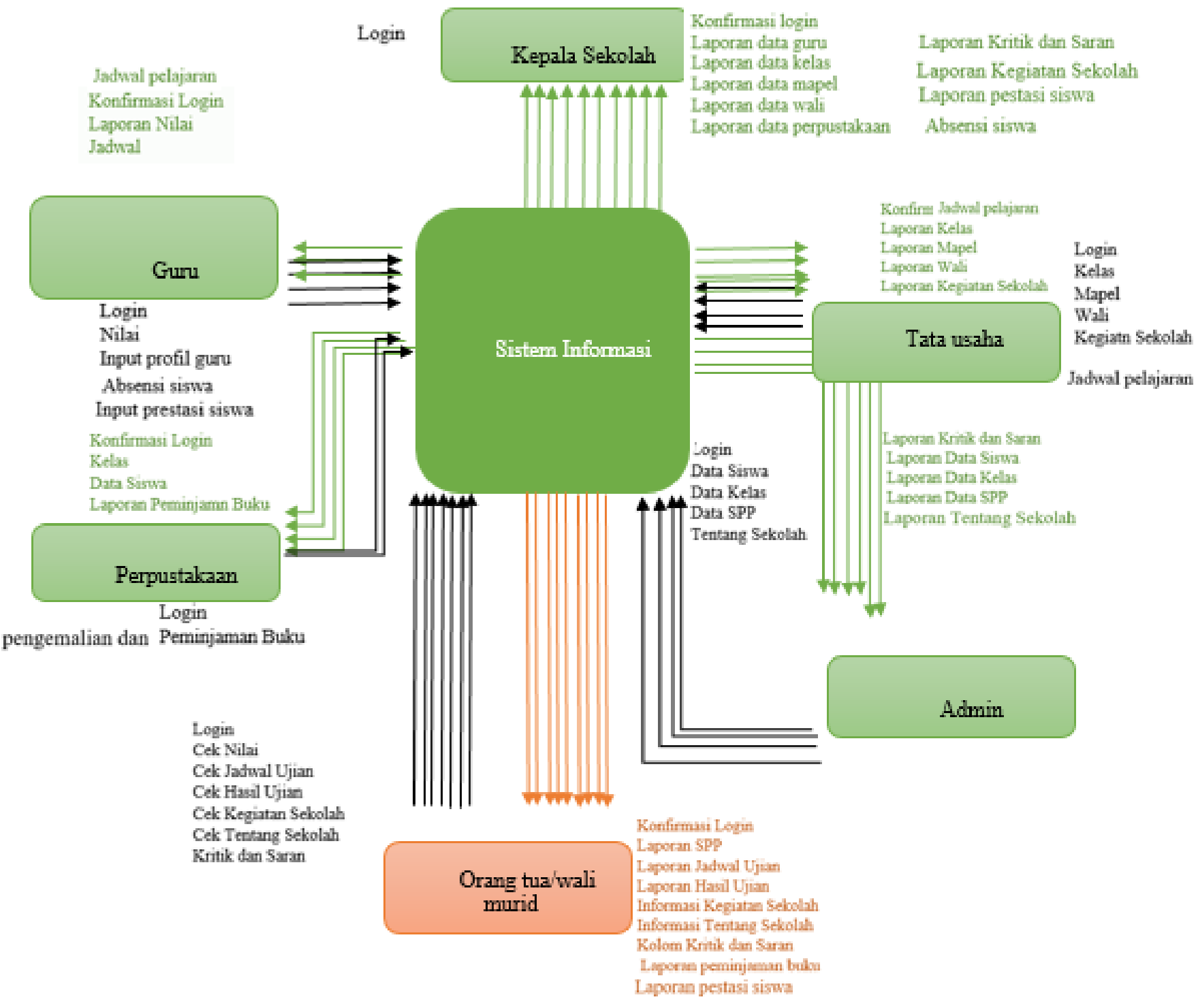

Diagram 1. Use Case pada Sistem Informasi Sekolah MTsN 8 Bantul

\section{KESIMPULAN}

Kesimpulan dari paper ini adalah memberikan solusi berupa rancang bangun sistem informasi pengolahan dan penyimpanan data yang efektif, rancang bangun ini juga dapat memudahkan pihak programmer untuk membuat suatu program sistem informasi sekolah. Selain sebagai rancang bangun ini juga sebagai bukti bahwa MTSN 8 Bantul ikut serta dalam melaksanakan rencana pemerintah dalam melakukan digitalisasi data sekolah.

\section{REFERENSI}

[1] S. Putrawangsa and U. Hasanah, "Integrasi Teknologi Digital Dalam Pembelajaran Di Era Industri 4.0 Kajian dari Perspektif Pembelajaran Matematika," J. Pemikir. dan Penelit. Pendidik., vol. 16, no. 1, pp. 42-54, 2018.

[2] A. Dan, P. Strategis, S. Dan, and T. Informasi, "Jurnal Sistem Informasi ( Journal of Information Systems ). $1 /$ 12 ( 2016 ), 15-29 DOI : http://dx.doi.org/10.21609/jsi.v12i1.457,” vol. 12, pp. 15-29, 2016. 
Procedia of Engineering and Life Science Vol. 1. No. 2 Juni 2021

Seminar Nasional \& Call Paper Fakultas Sains dan Teknologi (SENASAINS 2 ${ }^{\text {nd }}$ )

Universitas Muhammadiyah Sidoarjo

[3] R. T. Sataloff, M. M. Johns, and K. M. Kost, "JURNAL SISTEM INFORMASI JOURNAL OF INFORMATION SYSTEMS."

[4] Y. B. Siregar, "Digitalisasi Arsip Untuk Efisiensi Penyimpanan dan Aksesibilitas," J. Adm. dan Kesekretarisan STKIS Tarakanita, vol. 4, no. 1, p. 1-19, 2019, [Online]. Available: http://www.jurnal.stikstarakanita.ac.id/index.php/JAK/article/view/192/135.

[5] R. Kementerian Pendidikan dan Kebudayaan, "Digitalisasi Sekolah,” pp. 1-36, 2019.

[6] Ms. Prof. Dr. Suryana, "Metodologi Penelitian: Metodologi Penelitian Model Prakatis Penelitian Kuantitatif dan Kualitatif," Univ. Pendidik. Indones., pp. 1-243, 2012, doi: 10.1007/s13398-014-0173-7.2.

[7] K. H. Dewantara and S. E-mail, "Deskripsi Kualitatif Sebagai Satu Metode Dalam Penelitian Pertunjukan," Harmon. J. Arts Res. Educ., vol. 11, no. 2, pp. 173-179, 2011, doi: 10.15294/harmonia.v11i2.2210.

[8] Turisto, "PENGGUNAAN METODE WATERFALL UNTUK PENGEMBANGAN SISTEM MONITORING DAN EVALUASI PEMBANGUNAN PEDESAAN," Notes Queries, vol. 182, no. 23, p. 321, 1942, doi: 10.1093/nq/182.23.321-a.

[9] J. Cordeaux, "IMPLEMENTASI MODEL WATERFALL PADA PENGEMBANGAN SISTEM INFORMASI PERHITUNGAN NILAI MATA PELAJARAN BERBASIS WEB PADA SEKOLAH DASAR AL-AZHAR SYIFA BUDI JATIBENING,” Notes Queries, vol. s5-VII, no. 159, p. 37, 1877, doi: 10.1093/nq/s5-VII.159.37a.

[10] Aceng Abdul Wahid, “Analisis Metode Waterfall Untuk Pengembangan Sistem Informasi," J. Ilmu-ilmu Inform. dan Manaj. STMIK, no. November, pp. 1-5, 2020, [Online]. Available: https://www.researchgate.net/profile/Aceng_Wahid/publication/346397070_Analisis_Metode_Waterfall_Unt uk_Pengembangan_Sistem_Informasi/links/5fbfa91092851c933f5d76b6/Analisis-Metode-Waterfall-UntukPengembangan-Sistem-Informasi.pdf. 